\title{
AN EXPERIMENT IN PHOTOSYNTHESIS.
}

\author{
By John L. DAHL, \\ Normal School, Fredonia, N. Y.
}

The following very simple experiment does not, I believe, occur in the form submitted in any of the popular texts. It will doubtless prove of value to teachers of botany because of its simplicity and concrete application to thotosynthesis.

This experiment may follow that proving the necessity of sunlight for starch-making, or it may be used for the twofold purpose of proving the need for sunlight and carbon dioxide in photosynthesis.

Овјест: What results when green leaves are fed carbon dioxide and-are subjected to direct sunlight?

Apparatus: Two battery jars (or four), each with a glass funnel, ring stands, carbon dioxide generator, and a quantity of fręsh water cress.

Procedure: Place water cress plants with much leaf exposure under two funnels, and submerge each in a battery jar filled with clear water at the temperature of the room. Charge one jar with abundance of carbon dioxide by allowing the gas to bubble through the water and the plants. Place a test tube filled with water over the end of each funnel in order to collect whatever gas is generated by the plants. Place both jars, side by side, in direct sunlight. As a control, two jars similarly treated may be placed away from the direct sunlight. Thus:

Jar No. 1 charged with carbon dioxide and in direct sunlight.

Jar No. 2 not charged with $\mathrm{CO}_{2}$, and in direct sunlight.

Jar No. 3 charged with $\mathrm{CO}_{2}$, away from direct sunlight.

Jar No. 4 not charged with $\mathrm{CO}_{2}$, away from direct sunlight.

Results: One cannot fail to collect at least three test tubes of oxygen in as many hours in the jar chàrged with carbon dioxide and kept in the direct sunlight, provided the sunlight is continuous and bright. In the other jars, only a slight amount of oxygen accumulates, depending on the quantity of direct sunlight and of carbon dioxide present. The results are highly gratifying.

The leaves in the various jars can be tested for the presence of starch in the usual manner. The results are very satisfactory.

\section{FULLER'S EARTH.}

The Geological Survey's annual statement on fuller's earth is now available for distribution. According to this report the production of fuller's earth during $\mathbf{1 9 1 5}$ increased 6,920 short tons in quantity and $\$ 85,573$ in value over 1914 . 